\title{
Notes from the Field: The Humanitarian Crisis in Ukraine
}

\author{
John Quinn \\ Prague Center for Global Health, First Faculty of Medicine, Charles University of Medicine Prague, Czech Republic \\ Submitted: 4 May 2015 | Accepted: 16 May 2015 | Published: 9 July 2015
}

\begin{abstract}
Humanitarian crises are politically and socially charged, and as actors, donors and organizations move in to help, duplication of services can ensue. Despite the influx of humanitarian actors into the war zone of eastern Ukraine, more are still needed to address immediate threat to the health of more than 5 million at-risk people in the area. The humanitarian disaster in Ukraine requires fast support and stakeholder involvement to mitigate preventable death among at-risk populations. As the crisis unfolds and many more people are caught in the crossfire with no health security, WHO is leading the charge to organize healthcare and humanitarian action to relive human suffering and engender health security for all.
\end{abstract}

Keywords: complex emergency; conflict medicine; health security; humanitarian crisis; human security in war

\section{Introduction}

Former Ukrainian president Yanakovich's refusal to sign an agreement bringing Ukraine economically closer to the EU in November 2013 set off a political and social revolution. Perceived power vacuums prompted a pre-planned annexation of the Ukrainian Crimean Peninsula by Russia. Currently, Russia deploys lethal hybrid warfare with proxy Russian backed terrorists throughout two large regions, Donetsk and Luhansk, and is spreading and probing further west into the regions of Eastern Ukraine. Ongoing terror attacks in major cities throughout the country are spreading fear of a Russian campaign to take over all of Ukraine or spark further violence and obliterate human and health security for the region.

Millions of civilians have been caught in the middle, with only intermittent access to basic health and hygiene services and an overall deterioration in an already failed health security state in a European country. Ukraine is a fragile state and extractive practices over the past decade have given way to institutional decline and ministerial decay. The repercussions of this are a decrease in human and health security which is unable to weather any shocks in times of crisis and disaster. The humanitarian crisis that has erupted has proven how much human life can be lost in such a short period of inaction and non-intervention in global health.

\section{Institutions in Decay}

Extraction of wealth and institutional rot tore out any resilience mechanisms for territorial defense, as well as any capacity for offering basic services like primary or emergency health care that existed under post-Soviet rule. This is especially seen in the regions of Donetsk and Luhansk and has quickly spilled-over into the port city of Mariupol and, in the north, the regional capital and border city of Kharkiv. The recently lost city of Debaltseve, where civilian casualties piled up during a ceasefire that never began, highlights how Russian hybrid warfare grinds through the civilian population.

As the Ukrainian state reorients itself and is busy making monumental and frame-shift changes towards stable and transparent democratic institutions, the humanitarian sector has speedily risen to the challenge of filling many gaps to enable health security for those caught in the 
middle-if only fleetingly - starting from at the bottom of a deep hole and on the back foot. This short report from the field is to serve as a snapshot of the current health situation in Eastern Ukraine and map what players and actors are doing to encourage health and human security and mitigate morbidity and mortality for a country in a state of full-blown war.

\section{Health Security in Ukraine: A Snapshot of Spring}

The simple numbers put forward in many United Nations (UN) and World Health Organization (WHO) reports, and reiterated by multiple humanitarian and non-regulatory parties such as the Organization for Security Cooperation in Europe (OSCE), the International Committee for the Red Cross (ICRC) and many others, put just over 5.5-6 million people living in violence-affected areas in Ukraine. Extremely conservative estimates based surveys carried out in only selected areas due to security concerns designate roughly one million Internally Displaced People (IDPS), the majority of whom are found in the Kharkiv region which experienced daily city center explosions at governmental and civic locations, assassination attempts against military leaders and multiple improvised explosive devices (IEDs) targeting the courthouse and even the regional hospital during winter and spring. With this, there have been at least 7,300 reported killed and over 17,400 wounded in eastern Ukraine as of $15^{\text {th }}$ February [1]. Many unofficial estimates of the dead are far greater as the fog of war makes record- and data-keeping impossible.

No consistent number has been put forth for the amount of displaced peoples in Russia and other neighboring countries, whether forced or voluntarily, but some estimates assess that between 500,000 to 600,000 have crossed borders and are now in resettlement camps and some private homes.

As with all conflict and mass flows of displaced peoples, health risks increase as access to a paper-based primary healthcare system limits known medical histories, information about allergies, prescription medications' names or dosages. Poor patient knowledge of their own health conditions is rooted in the paternalistic medical system of Ukraine. Children's vaccine records have also been lost and there is no access to basic care while on the run from fighting.

Inconsistent access to prescription medications exacerbates an already growing non-communicable disease (NCD) crisis as many reports by medics and the author of this paper find civilians and medics working in the field are asked for any anti-hypertensive medication for those in chronic crisis, cholesterol lowering medications, injectable insulin and other diabetes type II medications, which have long been cleared off the shelves. And with limited food supplies exacerbating poor medical outcomes and contributing to morbidity and mortality in addition to direct Russian mortar and Grad rocket attacks; the prognosis for human security is very poor. Indeed, NCDs for an ageing population throughout Eastern Ukraine is a major public health risk and concern when not at war, let alone with a breakdown of public serves [2]. Access to pharmaceuticals for diabetes, hypertension and cardiovascular disease in many areas of Luhansk and Donetsk has been entirely disrupted and in most cases, are non-existent.

These and many other issues compound poorly addressed mental health risks for the civilian, military and volunteer defense populations exposed to combat-related stressors. Such stressors can include extended aerial bombardment, not knowing the status of family members, kidnappings, public assassinations, starvation or any number of other lethal acts of violence which occur hourly amid peace talks and ceasefire negotiations that few combatants consistently follow. These acute factors act as major stressors for an already deteriorated health security situation across Eastern Ukraine.

Beyond NCDs is the more acutely-needed emergency medical care in a healthcare system and infrastructure which is not prepared for battlefield trauma. The term "battlefield" relates to all things pre-hospital as hybrid warfare takes place in schools, metros, soccer fields or any other place where local populations and potential targets may gather. Ex-hospital and emergency medical services have depleted to the level that there are only volunteer-based bullet hole-ridden civilian unarmored trucks and scattered ambulances taking patients to hospitals without adequate supplies of medicines, doctors or nurses to staff the ambulances, as all have fled the violence and supplies have been long since exhausted.

As with a majority of human conflict, doctors are seen as pillars of the community offering not only health promotion but also hope and stability. However, in the midst of Russian hybrid warfare, health care professionals serve as soft wartime targets [3]. Violence against healthcare workers was reported during the main street protests in 2014 , including a case where police threw grenades into a makeshift field hospital where medical staff were treating people [4].

\section{Public Health}

Basic services like sewage, running water and heating in healthcare facilities are limited or entirely absent. Surgeons are having to learn on the spot how to treat wartime injuries and basic surgical supplies like c-arm $\mathrm{x}$ ray, portable ultrasound, central venous line access, disposable urinary bladder catheters, chest tubes and abdominal drains are no longer in supply. This significantly limits the capabilities of surgeons and trauma teams to treat all patients presenting signs of battlefield trauma. The Ministry of Health is completely inadequate at providing continuous medical supplies as well as capacity, resources and staffing. It also lacks the flexibility to make quick legislative changes to mitigate these shortcomings institutionally as volunteers and NGOs bang down doors trying to obtain aid and supplies to meet the acute need that is being felt. 
Ukrainian State institutions in and near to battleground activity can provide no health security for the chronically ill, the mentally ill, the disabled, women, the elderly or orphaned children. These highly vulnerable groups are in need of immediate protection, food and access to healthcare services. Many health partners are conducting field missions and assessments while the extreme winter temperatures are just beginning to make way for spring. As a means of mitigating this, a mobile hospital from the Regional Trauma Center based in Lviv, and a military hospital from Odessa have been deployed, with budding capabilities and resources. Most civilian mobile hospitals deployed are volunteer-based, and thus find it difficult to integrate into the governmental communications, procurement and staffing systems within the Ministry of Defence, let alone to get any protection when rocket attacks commence.

The Ukrainian government has requested a mobile hospital from United States State Department and the Californian Emergency Medical Services Authority (EMSA), which is run by US Federal Disaster Medical Assistance Teams (DMATs). Another promised NATO-based Role II medical facility is also in development, provided by the US Air Force to give medical care to all patients in need before shipping them to a safer location for further medical care. One of the main issues in sending such a major medical asset to support military operations and the civilian population is that the Ukrainian institutional capacity is lacking and may not be a viable partner to manage and run such a medical asset sustainably. Much work remains to be done to aid further non-lethal medical aid and mutual aid requested by Ukraine, Ukrainians and all those caught in the middle of fighting. In late April and early May 2015, NATO led an institutional- and policy-supporting conference for the Ministries of Defense and Health to support its Role II care of soldiers and civilians caught in the crossfire. Many NATO countries' military experts and policy advisors attended the conference. Unfortunately, fatally corrupt ministries and internal politics prevented any constructive moves at the conference to find workable solutions to the pre-hospital dearth of resources and public health crisis that plagues Eastern Ukraine.

\section{Humanitarian Financial Crisis}

Financial concerns at the Ministry of Health $(\mathrm{MoH})$ have become more pressing, and this holds true also for many other services providing health security to Ukrainians. The internal rot of corrupt procurement systems has led to institutional demise with criminal levels of incompetence. Reform of Ukraine's healthcare delivery system to change it from one based on Soviet-style secondary care to a primary care-based one able to tackle the mortality and morbidity crisis in the country is acutely necessary and still lacking to a point of enemy intent [5].

At the eleventh hour, the World Bank (WB) UnderDirector Paolo Belli, pushed forward many capacitybuilding programs to help bolster the healthcare systems on both the long and short term in late 2014. In early March 2015, the WB approved a US\$214.73 million loan for the Serving People, Improving Health Project to support the implementation of reforms and improve service delivery in Ukraine's health sector [6]. The new WB five-year project will seek to develop medical infrastructure and improve the quality of health services with the help of a new funding mechanism within hospitals, as well as enhanced primary and secondary prevention, early detection, and treatment of cardiovascular diseases and cancer. It is also expected to improve first aid and emergency services [6].

In mid February 2015, the International Monetary Fund (IMF) released plans for approximately US\$17.5 billion from itself and the international community to be allocated to stabilizing the Ukrainian economy. This financial injection will be a great boost for an economy where surgeons are instead taking jobs as taxi drivers because the state currency, the Hryvna (UAH), has fallen precipitously with no sign of wage increases to compensate. The IMF's Director commented, "Of course, resolution of the conflict, so critical for people, would also strengthen and speed up prospects for macroeconomic stabilization and growth" [7]. This needed growth will also bolster human and health security for those presently caught in the middle of fighting.

\section{Infectious Disease: Old Threats and New Risks}

Ukraine is not an endemic zone for infectious diseases. However, access to essential vaccines for flu, routine pediatric vaccinations like polio, tetanus and in some areas measles, are at very low levels or even entirely unavailable with local bureaucracy one barrier and the limited access of the primary healthcare setting another. With this, the Ukrainian health system was weak before the crisis and is now on the verge of collapse in areas affected by combat, areas with high IDP loads, and regions requiring surge capacity and resilience to disruption of service delivery from the human security crisis.

The average vaccination coverage in the country for some diseases is well under $40 \%$ [8]. In some regions and communities most children have not been vaccinated at all during the past months. Therefore, outbreaks of polio and measles are likely throughout the summer of 2015. About 30 to $70 \%$ of healthcare workers have fled the combat areas or died, so health care has broken down and no supplies are available to replenish stocks.

As access to Luhansk and parts of Donetsk is not verified. Due to the recent law that limits Ukraine's support to the Donbas region, many people living there are deprived of healthcare services. Reports about civilian casualties from Debaltseve are still pending, but since the beginning of the conflict in mid-April 2014 and until 19 February 2015, at least 5,793 people (including 63 children) were killed and 14,595 (including 169 children) were wounded in the east of Ukraine [9,10].

During the second half of 2014, given the large population displacement and the lowest immunization coverage 
in Europe, Ukraine is at high risk of communicable disease outbreaks, especially among children. As the result of a financial deficit, an ineffective procurement system and the crisis, the government tender process for procurement of vaccines for 2014 in Ukraine has not been fully implemented. Regional stocks of vaccines have already been exhausted.

With further delays in procurement, the gap in vaccine supply is expected to continue. For a long period, UNICEF and WHO have been working with the authorities to improve all pillars of the immunization management system. At the time of writing, the Ministry of Health, together with UNICEF and WHO, and supported by the Governments of Canada and the USA, are in the process of filling some of the gaps by procuring polio vaccines. Draft Laws 2150 and 2151 pertaining to this topic were registered at the Verkhovna Rada of Ukraine on 17 February. These laws will allow state procurement of medicines and vaccines to be delegated to UNICEF and WHO [9].

The HIV/AIDS epidemic in Ukraine is one of the fastest growing in the world.Moreover, according to WHO, Ukraine is among the 27 highest multidrug-resistant tuberculosis (MDR-TB) burden countries in the world. Despite the adoption of the Stop TB Strategy by the National TB Programme (NTP), its components have not been sufficiently implemented. Financing of TB control activities mainly depends on the commitment and capacity of each oblast health administration. Laboratory capacity is limited and case detection efforts mainly focus on mass screenings of the general population.

Priority is given to hospital-based treatment and appropriate treatment depends on the local capacity to purchase the drugs. Provision of directly observed therapy (DOT) is lacking and patient support is limited. MDR-TB control activities are inadequate, as are efforts to address TB/HIV co-infection. There is a lack of anti-TB drugs in the country because of inadequate drug supply management and problems with the procurement of quality-assured drugs. The recording and reporting system is suboptimal, and expansion of the application software for a nominal electronic database is slow.

\section{Health Systems Affected}

The ongoing crisis has had a direct effect on the health of the population, resulting in trauma, including injuries and burns. Adequate emergency medical services, including well equipped ambulances, trained first-aid personnel and health workforce, intensive care facilities, surgeries and burns units, as well as medications and consumables, are insufficient and making them immediately available is a top priority [11].

Needless to say, in late November an OCHA report commented that the humanitarian community remains deeply concerned by the Ukrainian Government's announcement that all governmental services and personnel will be withdrawn from areas controlled by armed groups by 1 December (Decree 875/2014). The fear that this edict will worsen the humanitarian disaster unfolding in hard-toreach conflict areas controlled by armed groups is apparent. The health security of civilians is at great risk, with circumstances compounding the problems of a public health system already bursting at the seams.

As the Russian Ruble spirals out of control, the Ukrainian Hryvna is not far behind. This means that funds needed to buy food, and pay for heating supplies and essential medicines are not guaranteed-and in many areas entirely blocked. Moreover, the National Bank of Ukraine has worsened the crisis by closing down many of its operations and services in the East, which has caused disruption of state-funded pensions and disability payments.

\section{Improving Coordination}

These issues, among many others, threaten health security throughout Ukraine. But they are not new and have been tackled with varying degrees of success by government ministries, the humanitarian sector, and the many new volunteer groups which have appeared since the onset of violence and the decay of social order in Ukraine. As has been seen in many humanitarian disasters and public health catastrophes, many actors have immediately made efforts to address some of the numerous health-related shortcomings in health security. Such actors include international non-governmental organizations (INGOs), government bodies and ministries, loosely affiliated stakeholders and independent actors, but such fragmented efforts have led to a situation where many organizations are doing much the same thing with minimal benefit.

Due to security concerns, access to Donetsk and Luhansk is extremely limited, which in turn limits access for donors and organizations and minimizes their effectiveness. Due to the political and financial nature of donorbased organizations which provide medical care, technical assistance and other forms of direct emergency aid, their efforts are hampered by the factions imposing violence in these regions. In order to access these regions, organisations are confronted with Ukrainian Government forces and volunteer battalions (as of spring 2015 almost all volunteer units have been absorbed into Ukraine MoD) loosely loyal to them (but answerable only to their benefactors), separatists and Russian or Russian-backed troops.

Of course, no war is clear-cut with easy distinctions between sides and combatants, or which acts of violence are acceptable and which are not. The war in Ukraine is no different. OSCE has done a fine job of observing this violence but its representatives may be compromised in many locations as the Russian Federation is a member of OSCE and as Russia is not an official actor in the violence and conflict in Ukraine many of the Russian-speaking representatives of the OSCE in Ukraine are in fact loyal to Moscow.

The precarious security situation has led to stove-piped programs and the presence of multiple actors who are unwilling to communicate and share information and data 
across organizational boundaries. This duplication of aid sees two or more organizations at addressing the region's immediate needs based on information that may be dated or one-sided and politically- or financially-motivated.

An example of such a problem was seen in late August 2013, when fighting was escalating daily and many combatant and civilian deaths were being reported across the regions (oblasts) of Eastern Ukraine. To provide support for emergency medical aid, ICRC, WHO, International Medical Corps (IMC), Doctors Without Borders, local oligarchs from both sides and various other INGOs started to send everything from boots to diapers to first-aid kits of varying quality, as well as offering medical support to perfectly well functioning medical care facilities (MCFs). The resource- and labor-intensive acts of acquiring medical equipment both inside and outside of Ukraine, sending it to high-conflict areas with security-approved convoys, and offering a greater or lesser degree of training or inservice on newly offered equipment costs are logarithmic and were being duplicated.

Due to this, WHO, supported by OCHA, established the Health Sector in February 2014, and since then has been providing leadership and coordination to support both national and local health authorities in Ukraine. Moreover, WHO has been coordinating the collection, analysis, dissemination and communication of essential information on health risks, health needs and health sector responses, gaps and performance.

Despite there being more than 50 registered partners in the Health Cluster, only a limited number are actually providing assistance. WHO provides technical assistance appropriate to the health needs of the emergency (including the provision of health policy and strategy advice; promotion of expert technical guidelines, standards and protocols; best practice advice and implementation; and strengthening of disease surveillance and disease early warning systems). In order to provide this, WHO/Health Cluster flagship interventions include the Mobile Emergency Primary Health Care Units (MEPUs), Emergency Primary Health Care Posts (EPPs) and the provision of medicines. Donor funds that are provided to $\mathrm{WHO}$ are divided among the partners (e.g. The Ukrainian Red Cross, IMC). Moreover, WHO provides the core services for the Health Cluster (e.g logistics; the establishment of offices; surge and human resources management; procurement and supply management; administration, finance and grant management; support service delivery; inform HCT decision-making; planning and strategy development; and monitoring and reporting).

There are reports of Intensive Care Unit (ICU) ventilators and technical equipment being sent to functioning ICUs in Luhansk, small clinics and hospitals receiving the same first aid kits and incompatible medical supplies from disparate sources and medical teams arriving from abroad to the ATO offering surgical expertise in areas with an abundance of foreign-trained Ukrainian master surgeons in need of advanced surgical and diagnostic equipment, not expertise.

For example, the many peripheral injuries that occur with blast and sniper fire trauma require in-theater c-arm radiology capability, which doesn't exist in the ATO or in many areas throughout Ukraine, leading to external fixation of open fractures, which produces poor medical outcomes. The duplication of these services and support is not only a waste of valuable resource, it also shows that the international medical and health security response for the crisis is fragmented, poorly organized throughout and not unified in approach or goals.

This was no different with training initiatives for medical capacity building. Throughout Mariupol, Luhansk and Donetsk multiple teams heading to clinics and regional medical centers found that other local and international organizations had already been there, offering different levels of equipment and conflicting best practices in training. Sometimes groups arrive or depart within days of each other. This duplication does not help with capacity and it disrupts local operations and drains valuable resources with no stop-loss mechanisms.

In an effort to eliminate this duplication of basic and advanced emergency medical training for civil and defense forces, wealthy oligarchs have stepped-in to fill some gaps. Ukrainian patriots and philanthropists Elena and Viktor Pinchuk funded a Combat Medic program Medsanbat (medsanbat.info). This training system raises the medical standards in pre-hospital medicine for the military, volunteer battalions, police, trauma surgeons and emergency doctors in civilian hospitals, clinics and ambulances, the border guards and police and local civic volunteers helping regional humanitarian actors carry out their mission. The medical standards are rooted in North American prehospital and military medicine and follow the Tactical Combat Casualty Care (TCCC) guidelines and trauma protocols from Advanced Trauma Life Support (ATLS) and International Trauma Life Support (ITLS) for the very specific injuries caused by war and civilian healthcare support activities; many of them not seen by Ukrainian surgeons and physicians since World War II or while deployed to Iraq in 2004 to 2005.

Duplication has also been seen among the many volunteer and professional groups appearing and trying and teach the above-mentioned clinical standards. However, not all groups have the clinical and operational experience to provide and offer training and instruction based on any battlefield experience, knowledge of best practices for trauma or in experience dealing with conflict zones. However, in the pre-hospital medical community, the overriding conclusion is that in times of war and acute conflict any training that can be offered, even if it is sub-standard, is certainly better than none. Despite this, sometimes the message is mixed; if clinical standards are not communicated, negative health outcomes can ensue. The need for a standardized approach is acute. 


\section{WHO Can Fix It}

The unified health leadership necessary to reign in outlier organizations and actors and collate goals and activities to promote health security for eastern Ukraine is lacking. However, Dr. Dorit, the WHO Director for Ukraine and a fast and efficient health operator, quickly identified some of this duplication and pushed $\mathrm{WHO}$, as the leading organization, to move all health and medical related actors under its umbrella organisation.

This was first done in late summer of 2014, while many uncertainties of the conflict and the true needs were still being described and defined through ad hoc and weekly health sector meetings. These meetings were held with members of the Ministry of Health's Headquarters for Health in Emergencies (e.g. Schtab). However, poor collaboration and only tacit support from the Ministry of Health remained a barrier; endemic corruption and a drowning bureaucracy were overwhelmingly stifling the health security for the strangled population in the East.

Despite these challenges, Dr. Dorit and her team were able to promote emergency legislation to deliver polio and tetanus vaccines to the East where at the time emergency supplies had been depleted. Furthermore, despite the ongoing humanitarian crisis, access to pharmaceuticals ran up against further obstacles in the form of bureaucratic processes. With help from UNICEF, WHO has supported the Coalition Agreement of Parliamentary Fractions enabling reform to the preexisting system of procurement of medicines according to European standards and principles (procurement of vaccines and medicines directly from the manufacturer).

2015 will be a transitional year in terms of reform procurement funded by the state budget and to purchasing medicines and vaccines through international agencies, such as WHO and UNICEF [12]. Additionally, the Ukrainian Cabinet of Ministers is preparing changes to the Decree on Pharmaceuticals to support recognition of medicines from countries with strong regulatory bodies including Australia, Canada, Israel, Japan, the United States and the European Union.

Dr. Dorit was also able to liaise with many regional and local healthcare facilities with exhausted supplies in Donetsk, Luhansk, and especially Mariupol before the onslaught of Russian tanks as the deadly offensive struck and the city fell under seige. However, escalation of the conflict and violence also meant that WHO had to escalate its response, organization and structure. Therefore, Dr. Dorit upgraded the Health Sector to the Health Cluster in order to strengthen response and support.

WHO has identified great gaps exist in terms of access to treatment for non-communicable diseases (NCDs), to pharmaceuticals and to ongoing care such as insulin, dialysis consumables, blood transfusions and primary and many emergency care medicines and supplies in hospitals, especially those with high concentrations of IDPs. To improve the capacity of the Ukrainian Ministry of Health to deal with the humanitarian crisis, WHO helped encourage the formation of the Department of Public Health which will be responsible for surveillance and action programs to address many of the aforementioned health security risks and shortcomings of the current system.

At a very practical level, $\mathrm{WHO}$ is providing the Dnipropetrovsk, Donetsk, Luhansk, Kharkiv, and Zaporizhzhia regions with Inter-agency Emergency Health Kits and is overseeing reproductive health kits issued for many regions. To be closer to the affected area, the WHO Field Coordinator established the main WHO Field Office in Kharkiv with the next to be set up in Mariupol and health assessments in the Izum and Kharkiv areas ongoing in order to identify their needs. Mobile Emergency Primary Health Care Unit (MEPU) teams are being recruited through the Ukrainian Red Cross and IMC in order to provide mobile primary healthcare services to IDPs and populations left without access.

Lastly, the WHO led Humanitarian Response website aims to streamline information sharing among the humanitarian community in Ukraine. It is easy to navigate and provides useful overviews of contacts, events/meetings, key documents, maps, infographics, statistics and other operational data that can help mitigate the duplication of services offered, focus activity in those areas with the greatest need, and help communication with governmental agencies and humanitarian actors.

For now, the most likely development for Russia is continued economic decline, with the main uncertainty centered on the effects the economic crisis will have on both Russian actions in Ukraine and on domestic stability [13].

\section{Disclaimer}

The author of this paper has conducted a Health Assessment for the Ukrainian World Congress in Summer of 2014 and is currently a Medical Consultant for Medsanbat. Much of the information gathered in this report is based on official and unofficial health data discussed and relayed by Dr. Dorit and her team at WHO, first-hand experience in the field, and other medical and health actor contacts throughout eastern Ukraine. The views expressed here are those of the author and do not necessarily reflect the views of any sources or governmental or non-governmental bodies or agencies, past, present or future.

\section{The Author}

John Quinn is a medical consultant specializing in conflict, disaster and emergency medicine. He holds Masters Degrees in Public Health and is both a paramedic and emergency medical doctor with over 15 years experience in Chicago, Peru, Iraq, Timor-Leste and Ukraine.

He designed, implemented and directed a telemedicine program for medical evacuation at an emergency operations center in Amman, Jordan; has performed emergency medical impact assessments in Ukraine, Israel and Pales- 
tine, Iraq, Kurdistan and Timor-Leste and has set up and operated remote medicine clinics in other conflict zones. $\mathrm{He}$ is currently completing his $\mathrm{PhD}$ in Hygiene and Epidemiology of fragile and failed states (2015). He worked as an emergency physician at a Level One Trauma Center in Ireland and as a locum physician in emergency depart-

\section{References}

[1] UN Human Rights Monitoring Mission in Ukraine and the World Health Organization's conservative estimates based on available official data. These totals include: Ukrainian armed forces casualties as reported by the Ukrainian authorities; 298 people from flight $\mathrm{MH}-17$; casualties reported by civil medical establishments and local administrations of Donetsk and Luhansk regions: and civilians and some members of armed groups (without distinguishing them). $\mathrm{OHCHR}$ and $\mathrm{WHO}$ believe that actual fatality numbers are considerably higher.

[2] Luck J, Peabody JW, DeMaria LM, Alvarado CS, Menon R. Patient and provider perspectives on quality and health system effectiveness in a transition economy: Evidence from Ukraine. Social Science \& Medicine. 2014;114:57-65.

[3] Quinn J, Mensah E, Hnillicova H, Bencko V. Iraqi Physician Brain Drain in Prolonged Conflict. The New Iraqi Journal of Medicine. 2011;7(1):88-98.

[4] Holt E. Health professionals targeted in Ukraine violence. The Lancet. 2014;383(9917):588.

[5] Hankivsky O, Vorobyova A. Health Care Delivery System: Ukraine. In: The Wiley Blackwell Encyclopedia of Health, Illness, Behavior, and Society. Wiley Blackwell; 2014. pp. 889-894.

[6] World Bank Provides Support for a Health- ments throughout the UK and Ireland. Dr. Quinn presently works between Eastern Ukraine and Iraq, providing emergency medical consulting and training in Tactical Combat Casualty Care and emergency medicine mentorship to local physicians. He is based in Prague with his family.

ier Ukraine. World Bank; 2015. Available from: http://www.worldbank.org/en/news/pressrelease/2015/03/04/world-bank-provides-supportfor-a-healthier-ukraine.

[7] Lagarde C. Statement by IMF Managing Director Christine Lagarde on Ukraine. Brussels, Belgium: International Monetary Fund; 2015. Available from: https:/www.imf.org/external/np/sec/pr/ 2015/pr1550.htm.

[8] Holt E. Health care collapsing amid fighting in east Ukraine. The Lancet. 2015;385(9967):494.

[9] Eurdolian A, Porter Z. Ukraine, Situation Report 28. United Nations Office for the Coordination of Humanitarian Affairs (OCHA); 2015.

[10] This is a conservative estimate from the UN Human Rights Mission in Ukraine (HRMU) and World Health Organization based on available official data.

[11] Center UMC. John Quinn: With the right training and equipment many lives of the soldiers could be saved;. Available from: http://uacrisis.org/9278-john-quinn.

[12] Porter Z. Ukraine, Situation Report 21. United Nations Office for the Coordination of Humanitarian Affairs (OCHA); 2014.

[13] Mankoff J, Kuchins A. Russia, Ukraine, and U.S. Policy Options: A Briefing Memo. Center for Strategic and International Studies; 2015. Available from: http://csis.org/files/publication/150129_Mankoff_ RussiaUkraineUSOptions_Web.pdf. 